\title{
Developing the information infrastructure based on LADM - the case of Poland
}

\author{
K. J. Góźdź*1 and P. J. M. van Oosterom ${ }^{2}$
}

In this paper, the possibilities of developing the national information infrastructure by applying the Land Administration Domain Model (LADM) are discussed. Confirmation of the legitimacy of using the LADM within the (Spatial) Information Infrastructure (SII) context is illustrated with the case of Poland. Creating the information infrastructure is an immense challenge because its components are usually dispersed among various institutions responsible for their maintenance and dissemination. Co-existing spatial and non-spatial components of the information infrastructure require their proper integration. Moreover, the interdisciplinary nature of the SII results in combining objects from physical and legal world in one computer environment. The process of standardisation is the first step to refine land administration system and to make it more understandable and transparent for involved parties. The LADM, being officially adopted as an international standard ISO 19152, gives a basis for building national profiles and supports creating the European information infrastructure, enabling communication based on common terminology. This paper provides a brief overview of the current land information system in Poland emphasising the main issues in creating the national information infrastructure. Then, the general concept of the country profile for Poland with the adaptation of the LADM is described. With respect to the users' expectations and requirements, the conceptual model is extended to information being outside the scope of LADM. As a final point, several technical aspects of implementing the complemented LADM country profile are explored. The results indicate that effective functioning of the information infrastructure requires proper integration of data, proceeded by analysing the contents of existing data sets, indicating key registers and defining a linkage system between them.

Keywords: Land Administration Domain Model, LADM country profile, ISO 19152, Harmonization, Information infrastructure

\section{Introduction}

The information infrastructure is an indispensable component of a modern state, supporting a sustainable development of the country and satisfying fast-growing information needs of its citizens. The dynamic development of methods and techniques of data acquisition gives the opportunity for their efficient and precise collecting and updating. Nevertheless, the essential problem is that data are usually dispersed in various data sets and maintained by different institutions. For the effective way of the information infrastructure functioning, it is required to harmonise data resources and indicate the key registers, as well as eliminate data redundancy and introduce unified data exchange standards.

The information infrastructure consists of co-existing spatial and non-spatial components. Geometric data play a significant role in the information chain, because

${ }^{1}$ Faculty of Civil Engineering and Geodesy, Military University of Technology, Gen. Sylwester Kaliski 2, 00-908 Warsaw 49, Poland

${ }^{2}$ Research Institute for the Built Environment (OTB), Delft University of Technology, Jaffalaan 9, 2628BX Delft, the Netherlands

*Corresponding author, Email: katarzynagozdz@o2.pl they enable visualisation of a shape and extent of objects or phenomena, what results in better understanding and interpreting alphanumerical, thematic data. In the context of the widespread information infrastructure usage, urgent needs for the insight into the integrated data have occurred more and more frequently.

In this paper, the possibilities of developing information infrastructure with the use of the Land Administration Domain Model (LADM) are discussed. There are several reasons in favour of applying LADM, among others:

1. The LADM provides a conceptual model based on the Model Driven Architecture strategy, where the Unified Modelling Language (UML) plays a crucial role in formulating information models. Using UML is beneficial because it enables mutual harmonisation of data sets and gives the possibility of introducing a reference to the commonly used schemas from ISO standards, e.g. geometry and topology.

2. The LADM refers to both spatial and non-spatial elements; hence its implementation gives the opportunity of creating relationships between spatial and non-spatial key registers.

3. The LADM supports land administration systems, which are in principle always related to spatial units that are cadastral parcels. At the same time 
cadastral parcels are included in Annexe I of the INSPIRE Directive as the reference data constituting 'a spatial frame' for other thematic data sets (European Parliament and Council, 2007).

4. The LADM constitutes a generic domain model, which is expandable. It means that even if the model is related mainly to the land administration, additional classes representing, e.g. physical objects being counterparts of legal spaces, can be added. This gives the possibility of creating a connection between LADM and other standards (e.g. national data models, INSPIRE Data Specification on Buildings).

5. The LADM delivers a basis for extending 2D spatial representation of objects into the third dimension.

6. The LADM reveals a possibility of making some improvements in the existing national (regional) land information systems and, in consequence, creating more efficient information chain.

Confirmation of the legitimacy of using LADM within the context of the information infrastructure is illustrated with the case of Poland.

The paper is organised as follows. The section 'National Land Information System in Poland' briefly presents current land information systems functioning in Poland. The section 'Main Challenges in Creating the Information Infrastructure' discusses main challenges in development of the national information infrastructure. The general concept of the country profile for Poland with the adaptation of the LADM is described in the 'LADM Country Profile for Poland' section. Moreover, to illustrate the flexibility of LADM, the conceptual model is extended to information about representation of physical features of utility networks, being outside the scope. The section 'Future Improvements Based on the LADM Country Profile' indicates future improvements resulting from applying the LADM country profile. The section 'Technical Approach Towards the LADM Country Profile' elaborates on technical aspects of the implementation of the ISO standard model. The section 'Summary and Recommendations' summarises the paper and concludes the major findings as well as gives directions for future research.

\section{National land information system in Poland}

The land administration in Poland is based on the realestate cadastre as well as the land and mortgage register. Information about utility networks is gathered in the geodetic register of public utilities and information about engineering constructions - in the database of topographic objects. There is also an additional source of information called a base map, which constitutes a cartographic product conducted for urban and rural areas intended for development.

Apart from spatial data sets, there are registers, which include information on natural persons (the electronic system for registration of the population) and legal entities (the national official register of business entities).

\section{Real-estate cadastre}

The real-estate cadastre constitutes uniform data sets including information about:
- parcels, in particular their location, boundaries, area, land use classification, soil quality and designation in the land and mortgage register

- buildings, among others their location, class (according to the Polish Classification of Types of Constructions), functional utility, living space, designation in the land and mortgage register (if necessary) and general technical details (year of construction, number of storeys, material of external walls, etc.)

- apartments (covering both residential and commercial units), in particular their location, permitted use, living space, information about appurtenances and designation in the land and mortgage register (if necessary).

The records contain also information about owners and other individuals and legal entities that possess parcels, buildings or apartments. (Minister of Administration and Digitization, 2013)

The register embraces the whole territory of Poland and is systematically updated. A descriptive part of the cadastre is kept entirely in a digital form, whereas cadastral maps are vectorised in $75 \%$.

The real-estate cadastre is maintained at the regional level by 379 county chiefs or presidents of cities governed under county laws. Moreover, the central repository of cadastral data se copies is developed within a long-standing undertaking of creating the Integrated Real Estate Information System in Poland.

\section{Land and mortgage register}

The land and mortgage register includes information about the legal status of properties. It constitutes a register of titles, coming out of German and Austrian traditions, and it is composed of individual units (records) called land books. Owing to the fact that establishing land books is not obligatory in Poland, the land and mortgage register contains records concerning $\sim 80 \%$ of real properties. (Rękawek Pachwicewicz, 2012)

Every land book is broken down into four sections:

- the first section contains a physical description of the property

- the second section reveals an owner and perpetual usufructee (where necessary)

- the third section contains encumbrances and restrictions in possession of the property (e.g. easements, usufructs, pre-emption rights, restrictions in disposals)

- the fourth section is related to mortgages.

The register is kept by district courts competent for the relevant territory of the state. The land and mortgage register, conducted previously in written form, has been almost entirely converted to electronic form. The contents of land books have been collected in the Central Database of Land and Mortgage Register, localised in the Main Centre of Data Processing of the Ministry of Justice.

Mutual exchange of the data between the real-estate cadastre and land and mortgage register has been guaranteed by legal regulations since 1983 . Cadastral institutions are responsible for the objective data, and local courts - for information about real property rights. Currently, the electronic notifications about changes are sent between systems and the updating processes are based on the object identifier or the number of land books. Unfortunately, there is still incomplete consistency of data in the real-estate cadastre as well as land and mortgage register, which is the result of long-term functioning of those systems as autonomous data sets. 


\section{Geodetic register of utility networks}

The geodetic register of utility networks gathers spatial and descriptive data on utility networks, which are defined in the Geodetic and Cartographic Law as installations and conduits used particularly for water supply, sewage disposal, gas supply, heat distribution, telecommunication and power supply, as well as underground structures, such as tunnels, underpasses, parking places (Polish Parliament, 1989). In connection with the fact that utility networks may be located above, on or below the surface of the ground, the register contains indirect information about third dimension. The records include also data about entities who are the owners of networks.

The geodetic register of utility networks is maintained by county chiefs or presidents of cities governed under county laws.

\section{Database of topographic objects}

The database of topographic objects in detail required for standard maps in scales 1:500-1:5000 is maintained for urban areas and rural areas, which are built up or intended for development. The database collects spatial and descriptive data concerning topographic objects. There are several categories of topographic objects, among others: constructions and engineering structures (excluding buildings), communication and transport, land cover and relief.

Similarly to the register of utility networks, the database of topographic objects is kept at the county level.

\section{Base map}

In the conventional approach, which has functioned within the last 20§years, the base map was a large-scale cartographic product and it contained information on spatial location of geographical objects, including cadastral objects and elements of utility networks. This approach resulted in double collecting and storing many spatial data sets. Moreover, in some cases the register of utility network was replaced by the base map, which caused inconsistency of geodetic data sources in local offices.

In the modern approach, the base map is a standard cartographic product created on the basis of relevant databases, taking into account the principle of interoperability (see Fig. 1). The integration of data from different individual sources gives the base map a character of the SII.
Nevertheless, in order to implement that approach the complete harmonisation of reference databases is required, so that all inconsistencies and data conflicts have to be identified and corrected at first.

\section{Electronic system for registration of the population and the national official register of business entities}

In Poland there are two separate registers that gather information on individuals and legal entities: the electronic system for registration of the population and national official register of business entities. Both data sets are kept in digital form.

The electronic system for registration of the population contains detailed information about all permanent residents of Poland and temporary residents living in Poland for $\sim 2$ months, as well as applicants for an identity card or passport, under the provisions of Polish law. The register is maintained by the Ministry of Internal Affairs.

The national official register of business entities includes information about legal entities, organisational units without status of legal entities and individuals running economic activities. The responsibility for keeping this register lies with the Central Statistical Office.

\section{Main challenges in creating the information infrastructure}

Development of the information infrastructure in Poland is a complex, long-term process in which many institutions are involved. There is a lack of clear data structures defined in UML and object-oriented approach in case of some databases. Common formats of the data exchange based on XML and GML have been introduced only recently.

Moreover, double collection and storage of the same data in several databases (e.g. personal data) has not been completely eliminated. Groothedde, Lemmen, van der Molen and van Oosterom, (2008) argue that the information content within the SII consists of several key registers and it is therefore important to define what contents belong to what register. The different databases within the SII are related, i.e. there are references in the content from one database to another, without

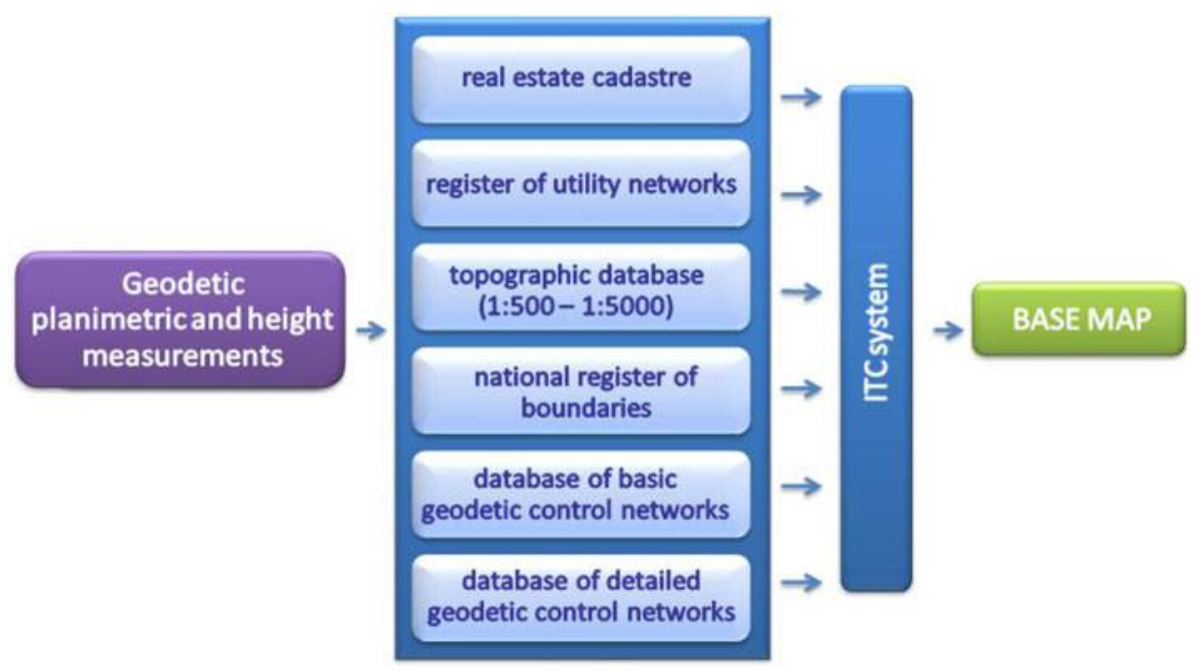


replication of the same data. It seems that the most efficient way of developing the information infrastructure is to indicate key registers at first and define a linkage system between databases.

From the perspective of the enhancement of legal security of the real property owners, the cadastral information should be supplemented with data concerning limitations in using of the space, caused by existence of the utility networks and engineering structures, such as tunnels or flyovers. That integrated information would allow gaining complete and comprehensive knowledge about real properties, which is about their legal status, the possibilities and limitations of their development, the influence of external factors on their value as well as the possible impact on the environmental protection.

Nowadays, Polish databases are not completely adjusted to fulfil the abovementioned requirements; hence, LADM is recommended to be used for eliminating some irregularities.

\section{LADM country profile for Poland}

This section presents the general insight into development of the Polish country profile with the adaptation of LADM. It should be noted that LADM officially adopted as the international standard ISO 19152, provides a basis for developing national profiles based on common terminology for land administration and enables combining land-related information from different sources in a coherent manner.

The LADM provides an abstract, conceptual model with three packages related to:

(1) parties (people and organisations)

(2) basic administrative units, rights, responsibilities and restrictions

(3) spatial units (parcels, and the legal space of buildings and utility networks), with a subpackage of spatial sources and spatial representations (ISO 19152, 2012).

During last several years, the possibilities of using the LADM as a reference for developing national land information systems has been investigated by several countries, among others: Portugal (Hespanha, 2012), Cyprus, Australia (Karki et al., 2011), Croatia, Brasil (dos Santos, Carneiro and Andrade, 2013), Hungary (Iván, 2013), the Russian Federation (Vandysheva et al., 2011) and Malaysia.

Adopting LADM in the Cyprus Land Information System (CLIS) will provide many benefits, including improvement in the efficiency and effectiveness of the system owing to better structuring of the rights, responsibilities and restrictions (and related source documents) as well as better usage of the information infrastructure both at the national and international level. Moreover, introducing LADM will streamline the expansion of the services provided by CLIS to the broader land administration system and to the Cyprus community (Elia, Zevenbergen, Lemmen and van Oosterom, 2013).

The LADM country profile for the Republic of Croatia served as the basis for remodelling existing national land information system to achieve a better connection between official registers and their adjustment to the electronic data processing. Implementation of the Croatian model of linking official registers, developed as an extension of LADM, will provide a flexible, sustainable and efficient integrated information system. Furthermore, electronic managing of data structured according to the above model will improve data quality (Mader, Matijević and Roić, 2013).

The proposal of a Malaysian LADM country profile takes into account different aspects of the ISO 19152 such as: 'RRRs' (Rights, Restrictions and Responsibilities), 'Spatial Units' and 'Parties', which are described in relation to $2 \mathrm{D}$ and $3 \mathrm{D}$ cadastral situations. During development of the conversion from a conceptual model (UML class diagrams) to database schema (SQL, DDL), the possibilities of using various data types with special attention to $2 \mathrm{D}$ and $3 \mathrm{D}$ geometries from the ISO 19107 have been considered (Zulkifli, Rahman and van Oosterom, 2013).

Among many countries, Poland is one of the potential candidates interested in using LADM-based country profile for the improvement of the existing land administration system. The main objective of elaborating Polish country profile presented in this section is to implement a new practical solution for the future land administration system, treated as a core in the national information infrastructure and based on ISO standards.

This section is also aimed at indicating key registers to create a better linkage of data sets and enable more efficient data exchange among different parts of the Land Administration system. For that reason selected classes from the conceptual model are distinguished, with the names of reference registers.

\section{Approach for modelling the LADM country profile for Poland}

The proposed LADM profile for Poland is modelled in UML and consists of three packages being counterparts of packages included in the ISO 19152. Classes from Polish land administration subsystems are modelled as subclasses of the LADM classes. In addition, they are distinguished with the prefix 'PL_'. This approach completely integrates LADM with the existing national data models.

In order to emphasise the possibility of adding information being outside the scope of LADM, the country profile is extended with the external UML classes representing the physical utility network data. In this way, the paper provides the general insight into how LADM can be extended for specific applications.

Although the ISO 19152 includes code lists with predefined values for several attributes, the Polish LADM country profile makes use of the national code lists. First, there are many cases when the ISO standard does not provide any values, which are essential in the context of the functioning of the Polish land administration. Moreover, there are no definitions for the code list values in LADM; hence it is difficult to decide which value would be the most appropriate. Finally, as the LADM code lists are nonnormative, there is no obligation to map Polish code lists to them.

\section{LADM country profile for Poland - Party Package}

Diagram Party Package presents the contents of a package related to parties in the Polish cadastral system (see Fig. 2). 'Parties' are defined in the ISO 19152 as persons or organisations (e.g. companies, municipalities, farmers cooperatives) that play a role in a rights transaction. (ISO 19152, 2012) 


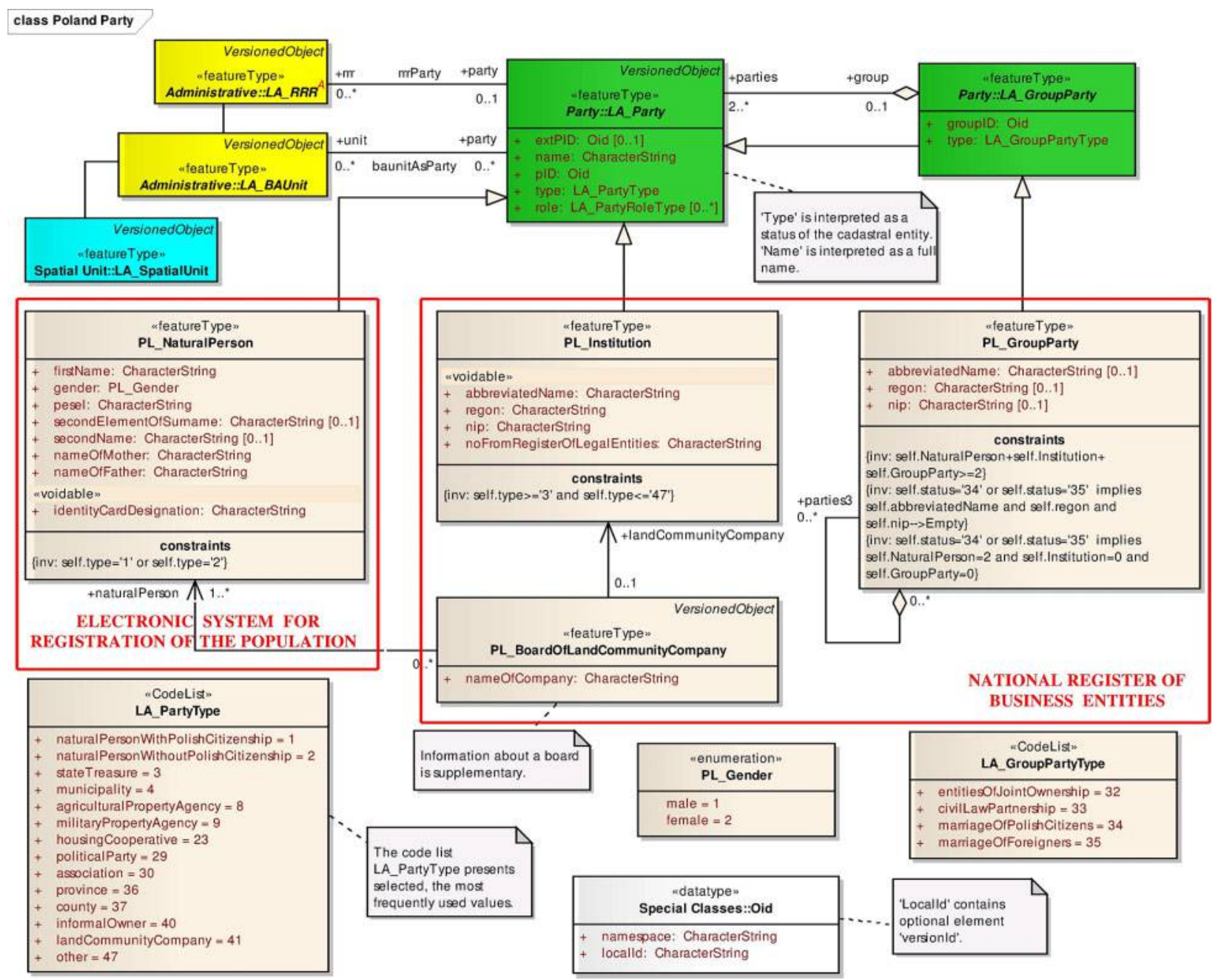

\section{The Polish Land Administration Domain Model (LADM) country profile - Party Package}

The inheritance structure indicates that LA_Party has two specialisations: $P L_{-}$NaturalPerson and $P L_{-} I n-$ stitution, as well as LA_GroupParty has one specialization: PL_GroupParty. In addition, the LADM country profile for Poland includes a class PL_BoardOfLandCommunityCompany, with boards of land community companies as instances. A land community company is usually established to manage common lands owned collectively and represents the interests of people having certain shares in the rights. The board is only the representative body, which does not have any property rights attached, which is why there is no generalisation relationship between LA_GroupParty and $P L \_$BoardOfLandCommunityCompany.

In Poland detailed information about individuals and business entities is the subject of registration in the electronic system for registration of the population and the national official register of business entities. It is recommended to derive and update information directly on the basis of these registers, as well as replacing double gathering of information with the linkage system.

In order to indicate the key registers in the conceptual model, selected classes are distinguished by red outlines, with the names of reference data sets (see Figs. 2-4).

\section{LADM country profile for Poland: Administrative Package}

The diagram Administrative Package presents the contents of a package concerning rights, restrictions, responsibilities and basic administrative units, in relation to Polish cadastral system (see Fig. 3). Modelling alternatives for rights, restrictions and responsibilities within the context of the LADM are discussed in detail in the study by Lemmen, van Oosterom, Eisenhut and Uitermark, (2010a).

According to the ISO 19152, 'right' provides a formal or informal entitlement to own or to do something. There are two types of rights: real rights and personal rights. Real rights are rights over or in respect of spatial units (e.g. ownership or usufruct). Personal rights are rights that parties have (e.g. fishing rights, grazing rights or use rights). A 'restriction' is a formal or informal obligation to refrain from doing something (e.g. a ban of building within $200 \S \mathrm{m}$ of a fuel station or a servitude as a restriction to the ownership right). A 'responsibility' is a formal or informal obligation to do something (e.g. the responsibility to clean a ditch or to keep a snow-free pavement).

The ISO 19152 introduces also a notion of 'baunit' (an abbreviation for a basic administrative unit). A 'baunit' is an administrative entity, subject to registration (by law), or recordation, consisting of zero or more spatial units against which (one or more) unique and homogeneous rights (e.g. ownership right or land use right), responsibilities or restrictions are associated to the whole entity, as included in a land administration system (ISO 19152, 2012).

In Poland, rights and restrictions are revealed in the land and mortgage register. Rights are ascribed to a real property (PL_RealProperty) which is a counterpart of 


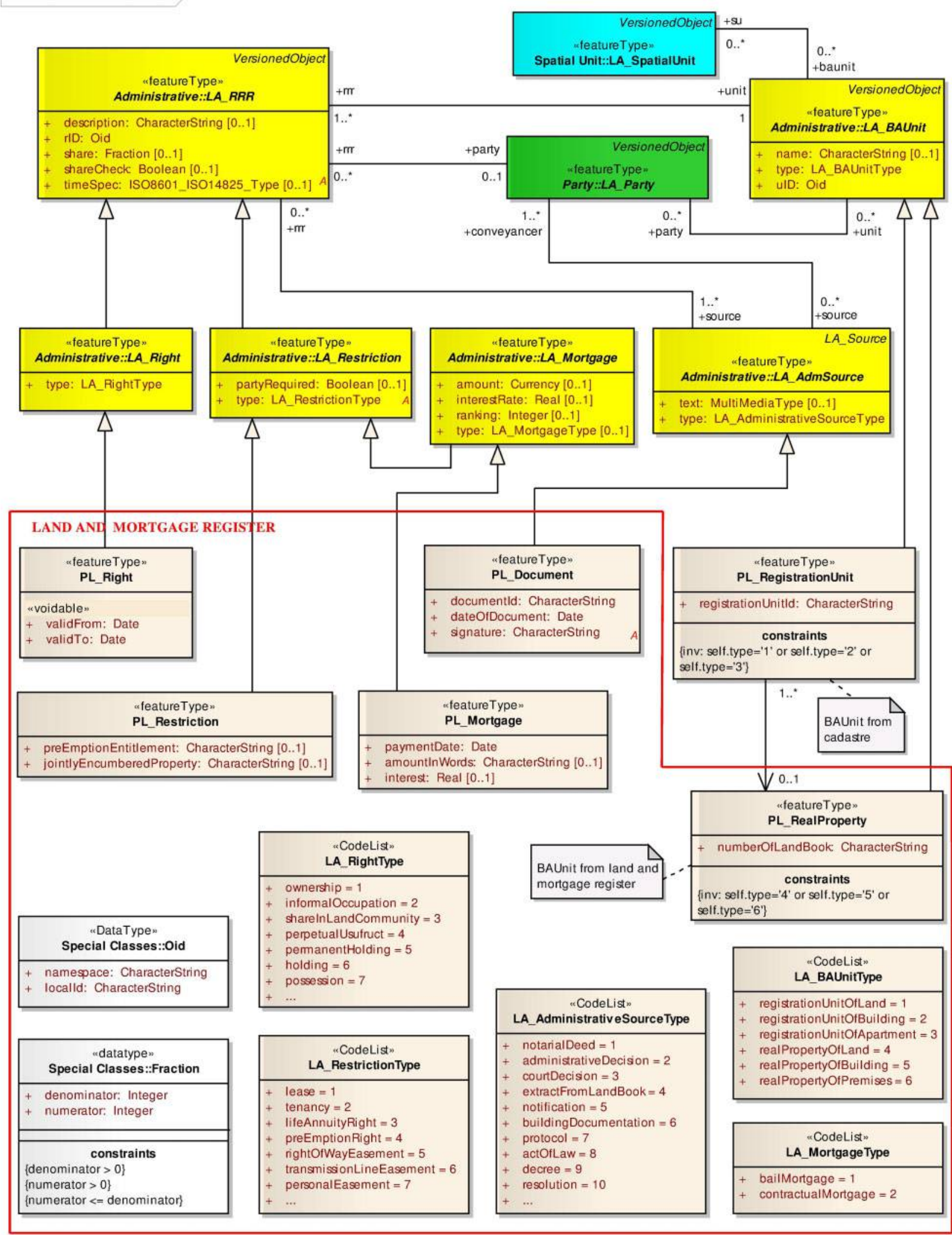

\section{The Polish Land Administration Domain Model (LADM) country profile - Administrative Package}

a basic administrative unit ( $\left.L A \_B A U n i t\right)$. It should be emphasised that establishing land books to real properties is not obligatory in Poland.

The second register that gathers information about real rights is the real-estate cadastre. In contrast with the land and mortgage register, the cadastre embraces the whole territory of the country and it reveals information about the ownership of all properties, including those lands, which are occupied informally. Moreover, in case of governmental properties the cadastre collects additional information about organizations, which administer the lands and about entitlements attached. 


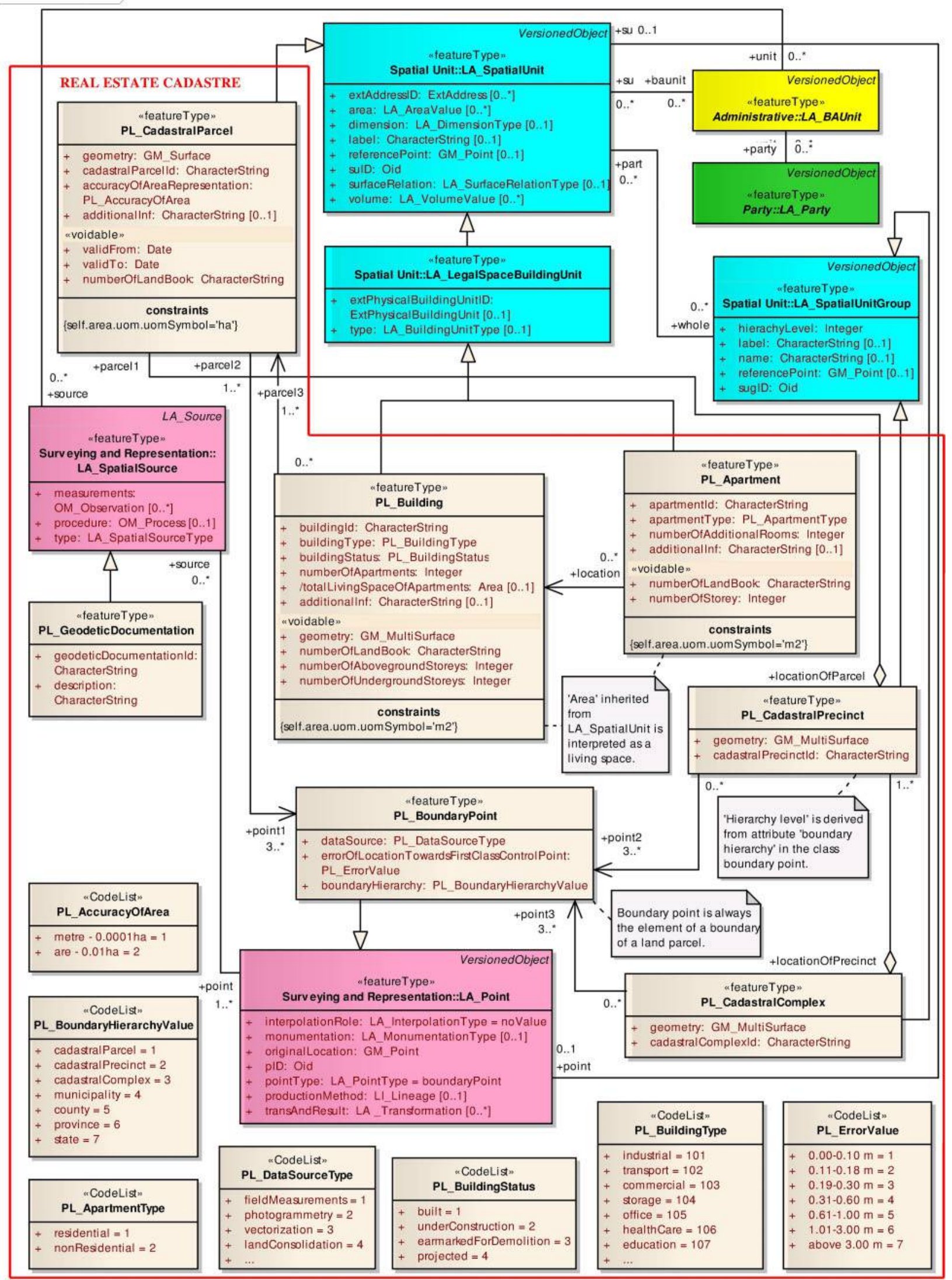

4 The Polish Land Administration Domain Model (LADM) country profile - Spatial Package 
One example may be the General Directorate for National Roads and Motorways (pol. Generalna Dyrekcja Dróg Krajowych i Autostrad (GDDKiA)), which is a public legal entity having a right of permanent holding (pol. trwaty zarzad) towards public lands occupied by roads. This information is included in the cadastre in the form of details about the GDDKiA (as an instance of PL_Institution) and description of the permanent holding right (as an instance of PL_Right).

In the cadastre, a registration unit ( $P L \_$RegistrationUnit) is a counterpart of a basic administrative unit (LA_BAUnit).

Figure 3 presents both $P L_{-}$RealProperty and $P L \_$RegistrationUnit, which are specialisations of LA_BAUnit. The above-mentioned classes fulfil the same role, but $P L \_$RegistrationUnit is used in the cadastre while $P L \_$RealProperty is used in the land and mortgage register. A real property is usually associated to one instance of the registration unit; however, it can be related to more instances in several cases. Example of this includes a situation when only a part of the property is the subject of lease. Then, there are two registration units established in the cadastre (for leased and nonleased part of the property), but the land and mortgage register reveals only one real property.

The Polish country profile based on LADM indicates overlapping information about rights in the real-estate cadastre and the land and mortgage register. In order to eliminate divergences between registers, the land and mortgage register is recommended as a key register with respect to legal status of properties. In addition, a thorough reform of collecting information in the central database of land books is required (currently no UML modelling, no object-oriented database).

\section{LADM country profile for Poland: Spatial Package}

The diagram Spatial Package presents the contents of a package related to spatial units in Polish cadastral system (see Fig. 4). The range of options available in the LADM concerning the spatial component is explored in the study by Lemmen et al., (2010b).

The LADM offers a generic spatial representation model for a variety of spatial units, i.e. land parcels, legal spaces around buildings and legal spaces around networks/utilities. Further 2D, 3D and mixed 2D/3D representations are supported with various levels of accuracy: text-based, point-based, unstructured (line)-based, polygon-based or topology-based. In order to organise all these options from the generic LADM spatial representation model, a number of spatial profiles are introduced.

Within the Surveying and Representation Subpackage there are three classes used for spatial representation: 'points' which are zero-dimensional geometric primitives representing position, 'boundary face strings' used to represent the boundaries of spatial units by means of line strings in 2D and 'boundary faces' used in the 3-dimensional representation of boundaries (ISO 19152, 2012).

In Polish cadastre, there are three types of spatial objects: land parcels, buildings and apartments. It should be explained that for buildings two legal registration cases can be distinguished. A building may be an element of a land parcel (with the same owner) or it may constitute a separate building real-estate (then an owner of a land parcel and an owner of building are different). The cadastre includes data about both types of buildings.

The variety of information about parcels, buildings and apartments results from the fact that the cadastre is a multipurpose register used for many public tasks, inter alia spatial planning, taxes and fees assessment, denotations in the land and mortgage register, national statistics, farm registry and INSPIRE requirements. For that reason, the cadastre contains information associated not only with legal spaces of cadastral objects, but also their physical features.

In Fig. 4, some attributes of classes $P L \_$Building and PL_Apartment, which can be found in the Polish cadastre are omitted to distinguish information connected with legal spaces. The examples of skipped attributes are a function of the building, materials of external walls and a number of rooms or detailed information about the range of building reconstructions. According to assumptions of the Annexe $\mathrm{K}$ of the ISO 19152, an external class ExtPhysicalBuilding Unit is a representative of buildings as physical objects at the conceptual level.

In principle, the need for finding an explicit relationship between objects from legal and physical world is essential. The display of physical objects gives the reference to understand the location and size of the legal spaces. In case of Poland, the cadastre includes both information about legal and physical features of buildings; however, in other countries, the links between different data sources are usually required.

Moreover, the legal space may 'contain' different physical objects (engineering constructions, pipes, poles), which influence positively or negatively on the property usage, development and a value; therefore, this information should be available for the data users (future buyers, surveyors, assets valuers, the governmental services). It is recommended to integrate Polish cadastre with other key registers, such as the register of utility networks and topographic database, which will support the orientation of the legal spaces.

\section{Information about utility networks in the LADM country profile for Poland}

Information about physical features of utility networks is outside the scope of LADM. However, the informative Annexe $\mathrm{K}$ of LADM provides a stereotype class ExtPhysicalUtilityNetwork for the external registration of data about utility networks.

Classes that are outside the scope of LADM are represented as $<$ blueprint $>>$ stereotype classes. Their names start with the 'Ext' prefix, instead of the 'LA_' prefix.

The Polish register of utility networks plays a crucial role in investment processes and it is a significant database for creating a base map; hence, several data from this register are introduced to the LADM country profile for Poland (see Fig. 5).

The main class of the discussed package is PL_UtilityObject, with three specialisation classes: $P L \_$NetworkSegment, $P L \_$TechnicalDevice and $P L \_P o l e$. $P L_{-}$UtilityObject is an abstract class, which is introduced inter alia to manage and maintain historical data in the database. Classes PL_PowerCable, PL_PetrolPipe, $P L \_$HeatingPipe, PL_WaterPipe, PL_GasPipe, PL_TelecomunicationWire, PL_Sewer and PL_OtherPipeCable are subclasses of the class PL_NetworkSegment. Their instances represent different fragments of utility networks, 


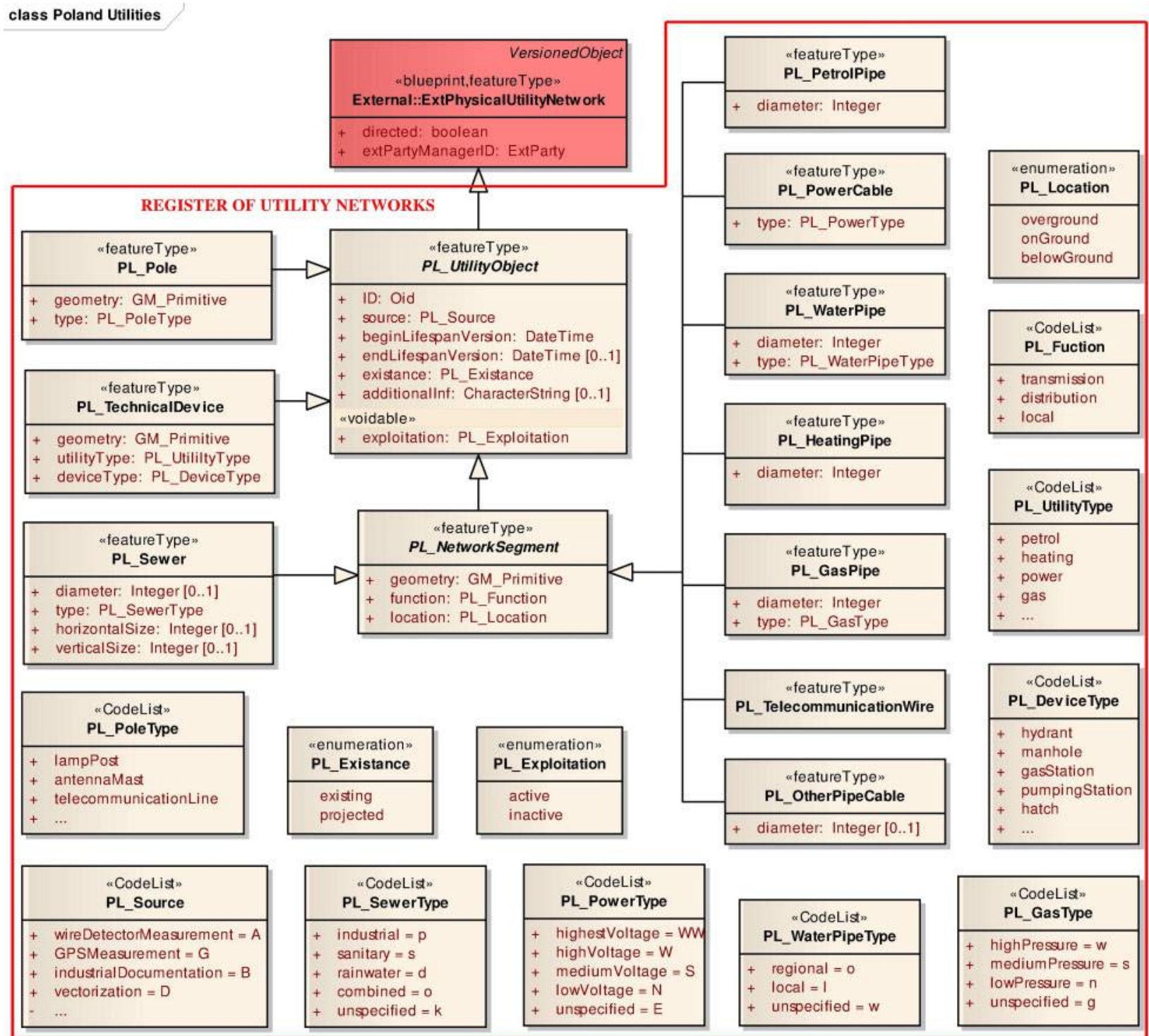

5 The Polish Land Administration Domain Model (LADM) country profile - external classes representing utility networks

which are segmented depending on a location in relation to the ground, a source documentation and the exploitation.

It should be underlined that nowadays the Polish cadastre has not revealed information about legal spaces of utility networks yet.

\section{Future improvements based on the LADM country profile}

Many improvements in the Polish land administration system require changes of legal regulations, and hence it is not possible to introduce them in a very short time. Nevertheless, in the long term, they are recommended as convenient solutions, which will be beneficial for developing the national information infrastructure.

As already mentioned above, the Polish cadastre includes variety of information about buildings. Data are related to both legal spaces occupied by buildings and their physical counterparts. Spatial representations of legal and physical objects may differ markedly. During the model designing process two alternatives have been taken into account:

(1) supplementing a class representing buildings with an attribute 'physical geometry' and storing two geometries of objects ('physical' and 'legal')
(2) introducing two classes that will represent 'legal' and 'physical' spaces of buildings in the cadastre. From the technical point of view the first solution is much more favourable, because its implementation does not require significant changes in the currently functioning database. The second option is definitely more invasive. On the other hand, the first alternative involves some difficulties. Even if legal spaces are closely related to physical objects, it is very risky to represent them in one class, because the change of features of physical objects may lead to serious consequences towards the legal spaces. An example can be a building being separate property, which has been demolished. Even if such a building no longer exists as a physical object, a legal space purchased by the owner is still undisturbed. For that reason, the second solution has been recommended for future applying.

The next issue is that the Polish cadastre does not currently reveal any information about the spatial range of the utility network legal space. The land and mortgage register includes only descriptive data about transmission line easement. It is important to realise that there is a difference between the physical object itself and the legal space related to this object. In case of utility networks, the legal space is usually larger than the 
physical extent of the object itself because it includes a safety zone (see Fig. 6). As a consequence, it is also recommended to introduce separate classes LA_LegalSpaceUtilityNetwork and ExtPhysicalUtilityNetwork with different attributes.

Finally, the Polish cadastral system meets serious complications with providing information about the legal status of real properties in case of $3 \mathrm{D}$ complex situations when different property units (with possible different types of use) are located above each other or constructed in more complex structures, i.e. interlocking one another. Owing to that fact the presented LADM country profile is proposed to be extended to a new class PL_3DParcel as a subclass of LA_SpatialUnit. The notion is described in detail in the study by Góźdź and Pachelski, (2014).

\section{Technical approach towards the LADM country profile}

This section outlines selected technical aspects of implementing the LADM standard as a core for developing the information infrastructure. Some proposed solutions are based on experiences drawn on assumptions made during execution of a project 'Preparation and implementing innovative methods of integration of cadastral data, base map and topographical database and modernisation of public services provided by Geodetic and Cartographic Service' (Mączewski and Janczar, 2010).

The main objective of the project is to prepare mechanisms for gathering, flowing and integrating data from geodetic registers conducted at various levels of the public administration. A basis for the data harmonisation constitutes the Generic Geodetic Model Ogólny Model Geodezyjny (OMG), based on the idea of the FIG Core Cadastral Domain Model (CCDM), published by Lemmen and van Oosterom, (2006). The CCDM has been a predecessor of the LADM. Currently, the Integrated System of Geo-referenced Data sets are developed on the basis of methodology prepared in the previous stage of the project.

The steps in developing the prototype system include among others:

- developing the exchange format (GML, XML)

- designing the database schemas

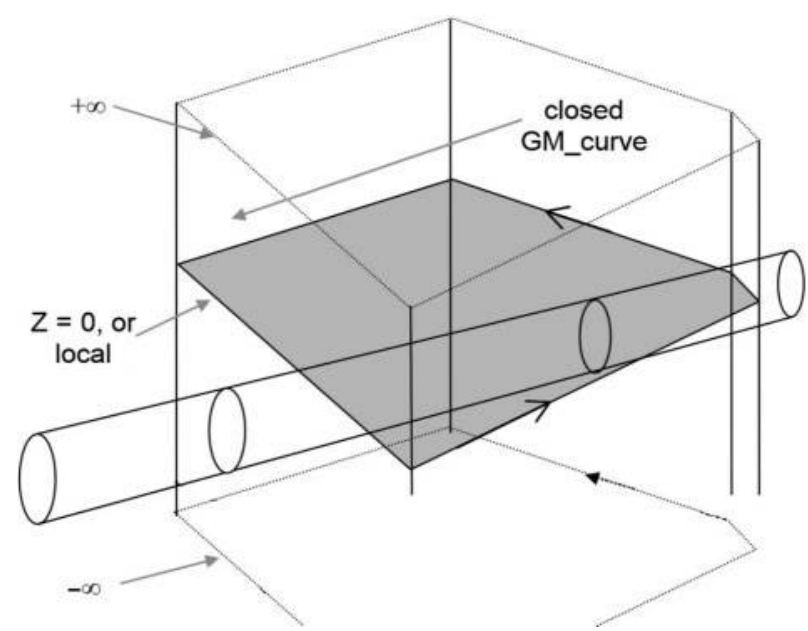

6 Example of a relationship between legal space of utility network and its physical extent (ISO 19152)
- creating a viewer and an editor tool.During the conversion from conceptual to technical model, many design decisions have been taken. Some proposed solutions are presented in this section. It should be noted that in this phase the nature of the issues is more technical and closer to actual implementation.

\section{Matching ISO data types with database environment}

Data types included in the LADM conceptual model (based on the ISO 19103 and ISO 19107) have to be assigned to relevant types in accordance with a specific database environment. In some cases it is not possible to match types directly. Then it is recommended to use a wider type in the database environment. An example can be 'Data Time' type, which has no counterpart in the types of the Oracle environment. Owing to that fact a type TIMESTAMP needs to be taken into consideration.

\section{Mapping relationship between two classes}

The 'one-to-many' association type can be mapped with the use of a primary key in the parent table and a foreign key in the child table. The 'many-to-many' relationships between classes can be implemented by means of additional intersection tables.

\section{Defining the structure of identifiers}

In the Polish land administration system, the structure of identifiers is represented by BT_Identifier and it consists of three elements: a namespace, a local identifier and a version (see Fig. 7).

It should be noted that the data flow between registers is carried out by invoking identifiers (see Fig. 8). With respect to that technical solution, the decision has been made to supplement the identifier structure with a version of the object in order to indicate precisely which version shall be referred. The solution is in accordance with principles described in the document 'INSPIRE Generic Conceptual Model' (INSPIRE Data Specifications Drafting Team, 2013).

In LADM, a slightly different solution is applied, but with the same results provided. The ISO 19152 introduces a generic data type Oid to determine the structure object identifiers. Oid includes two attributes: the local identifier and namespace. Apart from that, LADM classes inherit the attribute begin lifespan version from the class VersionedObject. In this way, information about the version of object is delivered.

Following INSPIRE Data Specifications expectations, a namespace pattern of the Polish ID is defined as: 'PL.PZGIK $<$ a data set number from the national register of spatial data sets and services $>$ $<$ abbreviated name of a public register $>$ '.

The examples of namespaces are:

- PL.PZGIK.46.EGiB: the namespace for a data set of the real-estate cadastre in Bieszczady County.

- PL.PZGIK.238.BDOT: the namespace for the topographic database in Ślaskie Province.

- PL.PZGIK.304.GESUT: the namespace for a data set of the register of utility networks in Piaseczno County.

\section{Preparing GML application schemas}

The UML application schemas have been converted directly to GML application schemas with a tool such as 
class Identifiers

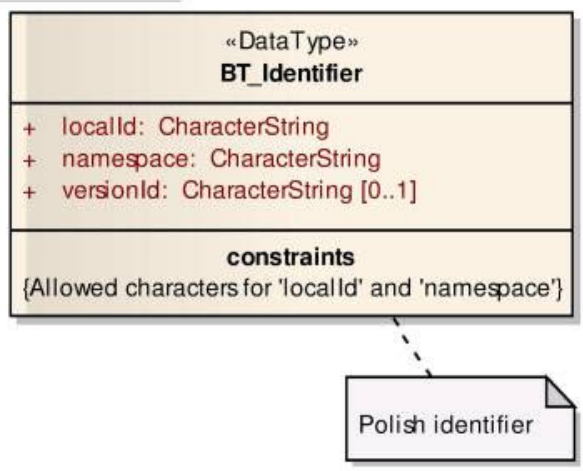

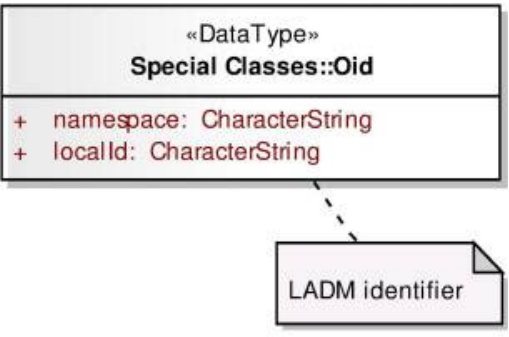

\begin{tabular}{|c|}
\hline "featureType" \\
Special Classes::VersionedObject \\
\hline+ beginLifespanVersion: DateTime \\
+ endLifespanVersion: DateTime [0..1] \\
+ quality: DQ_Element [0..*] \\
+ source: Cl_ResponsibleParty [0..*] \\
constraints \\
\{endLifespanVersion $(n-1)=$ startLifespanVersion $(n)\}$ \\
\hline
\end{tabular}

7 Structure of identifiers in the Land Administration Domain Model (LADM) and Polish databases

class Reference

\begin{tabular}{|l|l|l|}
\hline $\begin{array}{c}\text { "union" } \\
\text { ReferenceToObject }\end{array}$ & $\begin{array}{c}\text { "featureType" } \\
\text { ReferencedSpatialObject }\end{array}$ \\
\hline + idIIP: BT_Identifier & +object \\
\hline
\end{tabular}

\section{Reference between objects}

Enterprise Architect. The data exchange is based on GML and XML format files (see Fig. 9).

Not only the exchange format files (GML/XML) but also the database (SQL, DDL) can be derived from the UML class diagrams.

A database can be generated with the use of HyperJAXB3, which is an open source tool made in Java technology. The tool has to be configured properly to make the transition from the elements and types defined in the UML/XSD files to the database tables.

With the use of GML application schemas, it is also possible to build the data validator, which will verify the correctness of data submitted in GML files.

\section{Integrating data from different SII registers}

In order to assess cohesion of data in the system, an example of a base map is prepared (see Fig. 10). The base map has been created on the basis of data included in several public registers, which are elements (modules) of the system.

The example proves that owing to applying data harmonisation activities and developing the objectoriented system, it is possible to combine cadastral data with additional information from other registers being elements of the national information infrastructure.

\section{Summary and recommendations}

The paper explores the possibilities of applying the LADM to develop the information infrastructure, illustrated with the case of Poland. The conceptual model of the LADM country profile and its extension is described and some technical aspects are presented.
Developing the information infrastructure requires proper integration of data, proceeded by analysing the contents of existing registers and eliminating data redundancy. While preparing the LADM country profile for Poland, double collecting of data in several cases was revealed. In order to avoid data overlapping, the information infrastructure shall consist of several key registers (data sets) with defined non-repeated content. Moreover, the references between databases should be introduced by using the uniform object identifiers.

This paper proves the flexibility of LADM and the possibilities of using it for creating linkage between cadastral information (land parcels, property rights) and other characteristics, e.g. utility networks, topography and persons (van Oosterom et al., 2009). In this way, the land administration system may not only support registration of rights and spatial units, but also be used for serving other purposes, i.e. tax assessment, land valuation, environmental impact assessment, national security, subsidies for farmers, etc.

The increasing complexity of built structures as well as considerable growth of engineering constructions and elements of public utilities, located above or below the ground, intensify the need of developing 3D cadastral registration. In connection with that, further research will be devoted to define $3 \mathrm{D}$ spatial representations of those objects in accordance with types of spatial units and spatial profiles described in the ISO 19152.

The future research and development activities will also include the integration of objects from physical and legal world based on linking of the LADM-3D with CityGML (OGC standard for 3D city objects based on 

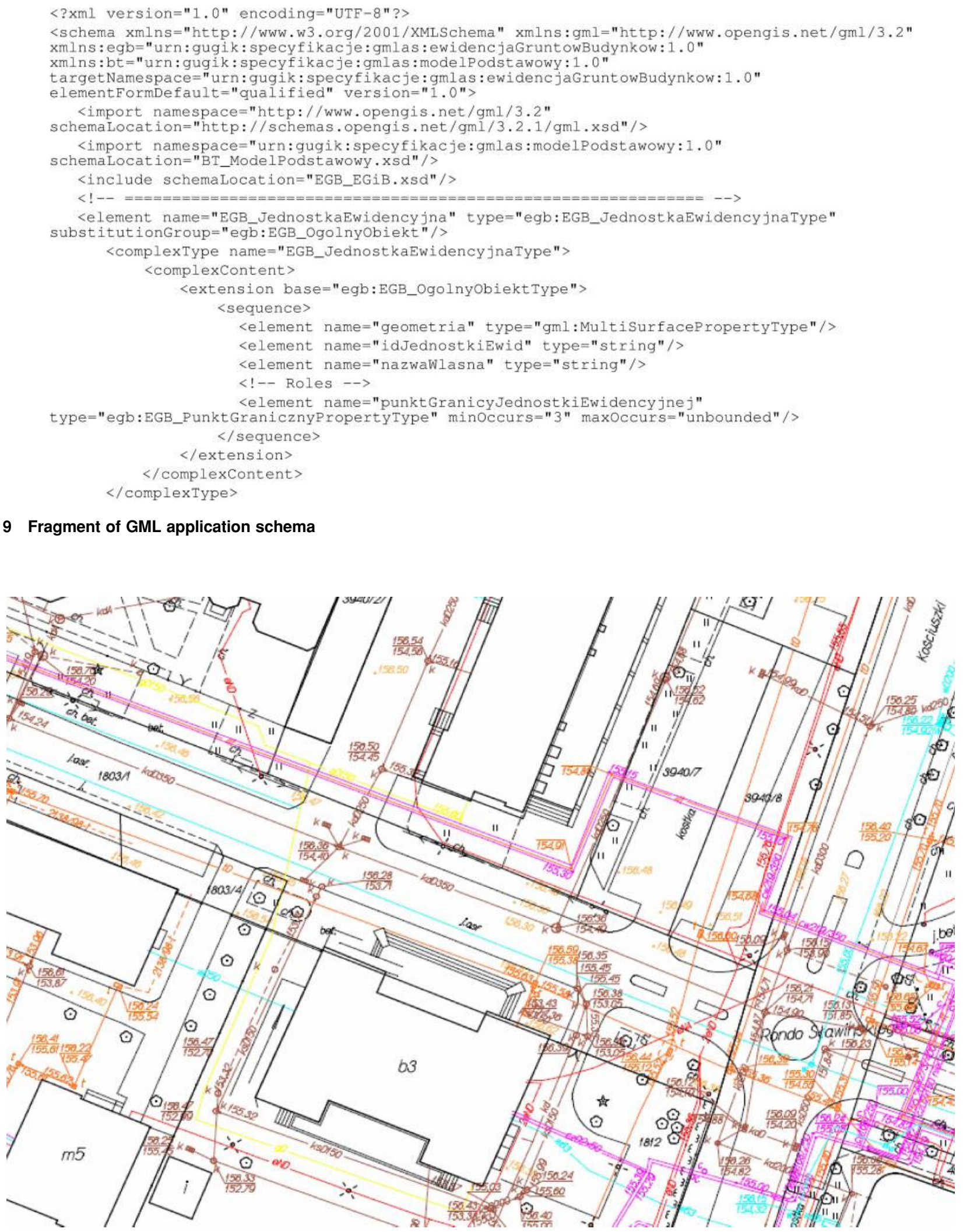

10 Fragment of a base map

GML (XML encoding)). This solution allows explicit relationships between a $3 \mathrm{D}$ cadastral object (e.g. legal space of building unit) and its physical counterpart (e.g. a part of building from CityGML).

Then, the next step will be to develop the $3 \mathrm{D}$ prototype and to assess its functionality before actual implementation in the productive environment.

\section{Acknowledgements}

The authors would like to thank the anonymous reviewers for their helpful and constructive comments that greatly contributed to improving the final version of the paper. They would also like to thank the editors for their generous comments and support during the review process. 


\section{References}

dos Santos, J. C., Carneiro, A. F. T. and Andrade, A. J. B. 2013. Analysis of the application of LADM in Brazilian Urban cadastre: a case study for the city of Arapiraca, Brazil. The 5th land administration domain model workshop. Kuala Lumpur, Malaysia, 24-25 September 2013.

Elia, E. A., Zevenbergen, J. A., Lemmen, C. H. J. and van Oosterom, P. J. M. 2013. The land administration domain model (LADM) as the reference model for the Cyprus land information system (CLIS). Survev Review, 45(329), pp. 100-110.

European Parliament and Council. 2007. The directive 2007/2/EC of the European parliament and of the council of 14 March 2007 establishing an infrastructure for spatial information in the European community (INSPIRE). Official Journal of the European Union, 108, pp. 1.

Góźdź, K. J. and Pachelski, W. 2014. The LADM as a core for developing three-dimensional cadastral data model for Poland. The 14th international multidisciplinary scientific geoconference SGEM 2014. Albena, Bulgaria, 17-26 June 2014.

Groothedde, A., Lemmen, C., van der Molen, P. and van Oosterom, P. In: P. van Oosterom and S. Zlatanova, eds. 2008. A standardized land administration domain model as part of the (spatial) information infrastructure, Creating spatial information infrastructures. Towards the spatial semantic web. Boca Raton: CRC Press, pp. 129-150.

Hespanha, J. P. 2012. Development methodology for an integrated legal system - deriving Portugal country model from land administration domain model. PhD thesis. Delft University of Technology, Netherlands.

INSPIRE Data Specifications Drafting Team. 2013. INSPIRE generic conceptual model (D2.5: generic conceptual model, V 3.4rc3). [Online]. Available at: <http://inspire.ec.europa.eu/documents/ Data_Specifications/D2.5_v3.4rc3.pdf $>$.

ISO 19152. 2012. International standard, geographic information - land administration domain model (LADM). Geneva, Switzerland: Technical Committee ISO/TC 211, Geographic Information/ Geomatics.

Iván, G. 2013. Hungarian cadastre and its relation to LADM. CLGE General Assembly, Budapest, Hungary.

Karki, S., Thompson, R., McDougall, K., Cumerford, N. and van Oosterom, P. J. M. 2011. ISO land administration domain model and landXML in the development of digital survey plan lodgement for 3D cadastre in Australia. The 2nd international workshop on $3 D$ cadastre. Delft, Netherlands, 16-18 November 2011
Lemmen, C. H. J. and van Oosterom, P. J. M. 2006. Distributed cadastral systems: FIG core cadastral domain model, version 1.0. GIM, 20(11), pp. 43-47.

Lemmen, C. H. J., van Oosterom, P. J. M., Eisenhut, C. and Uitermark, H. T. 2010a. The modelling of rights, restrictions and responsibilities (RRR) in the land administration domain model (LADM). FIG congress 2010, facing the challenges building the capacity. Sydney, Australia, 11-16 April 2010.

Lemmen, C. H. J., van Oosterom, P. J. M., Thompson, R., Hespanha, J. and Uitermark, H. T. 2010b. The modelling of spatial units (Parcels) in the land administration domain model (LADM). FIG congress 2010, facing the challenges - building the capacity. Sydney, Australia, 11-16 April 2010.

Mączewski, K. and Janczar, E. 2010. Legislative initiative supporting georeference data modeling standards in Poland. INSPIRE conference 2010, INPIRE as a framework for cooperation. Krakow, Poland, 22-25 June 2010.

Mađer, M., Matijević, H. and Roić, M. 2013. Linking land registers and other official registers in the republic of croatia based on LADM. The 5th land administration domain model workshop. Kuala Lumpur, Malaysia, 24-25 September 2013.

Minister of Administration and Digitization. 2013. The Decree of the Minister of Administration and Digitization of November 29 , 2013 changing the decree on real estate cadastre. Journal of Laws, 2013, entry 1551.

Polish Parliament. 1989. The Act of May 17, 1989 - The Geodetic and Cartographic Law. Journal of Laws, 2010, No. 193, entry 1287 with further amendments.

Rekawek Pachwicewicz, M. 2012. Land registry in Poland. [Online] Brussels, Belgium: XVI ELRA Assembly. Available at: < http:// www.elra.eu/xvi-elra-assembly/> [4 December 2012].

van Oosterom, P. J. M, Groothedde, P., Lemmen, C. H. J., van der Molen, P. and Uitermark, H. T. 2009. Land administration as a cornerstone in the global spatial information infrastructure. International Journal of Spatial Data Infrastructures Research, 4, pp. 298-331.

Vandysheva, N., Ivanov, A., Pakhomov, S., Spiering, B., Stoter, J., Zlatanova, S. and van Oosterom, P. J. M. 2011. Design of the $3 \mathrm{D}$ cadastre model and development of the prototype in the Russian federation. The 2nd international workshop on 3 D cadastre. Delft, Netherlands, 16-18 November 2011.

Zulkifli, N. A., Rahman, A. A. and van Oosterom, P. J. M. 2013. Developing 2D and 3D cadastral registration system based on LADM: illustrated with Malaysian cases. The 5th land administration domain model workshop. Kuala Lumpur, Malaysia, 24-25 September 2013. 